\title{
Two-dimensional gas chromatography time-of-flight mass spectrometry-based serum metabolic fingerprints of neonatal calves before and after first colostrum ingestion
}

\author{
T. Miyazaki, ${ }^{*}$ K. Okada, ${ }^{*}$ T. Yamashita, $\dagger$ and M. Miyazaki $\dagger^{1}$ \\ ${ }^{*}$ Department of Veterinary Medicine, and \\ †Department of Biological Chemistry and Food Sciences, Faculty of Agriculture, Iwate University, Iwate 020-8550, Japan
}

\begin{abstract}
Neonatal calves show a remarkable increase in serum IgG levels after first ingestion of colostrum. They can absorb high-molecular IgG from colostrum in the small intestine by nonspecific receptor-independent fluid pinocytosis within $24 \mathrm{~h}$ after birth. However, little is known about the temporal changes in serum small-molecule metabolites, such as carbohydrates and AA, in neonatal calves after first colostrum ingestion. In this study, we examined temporal changes in serum metabolites of neonatal calves after first ingestion of colostrum by comprehensive 2-dimensional gas chromatography mass spectrometry (GC $\times$ GC-MS). Forty serum samples obtained from 5 calves at 8 time points between 0 and $12 \mathrm{~h}$ after first colostrum ingestion were analyzed in triplicate by $\mathrm{GC} \times \mathrm{GC}-\mathrm{MS}$. Multivariate analyses of $120 \mathrm{GC} \times \mathrm{GC}-\mathrm{MS}$ results revealed significant variations in the serum metabolites, primary individual differences among the calves, and secondary temporal changes within each individual calf. Several serum metabolites increased temporally after ingestion in each calf, but only a limited number of compounds were increased universally in all 5 calves. Eight compounds, including oligosaccharides such as lactose, were associated with temporal changes in IgG. Some essential AA that must be supplied from the diet increased temporally after ingestion, but differed from the temporal pattern of the oligosaccharides and IgG. These results suggest that the colostral contents may be absorbed by complex mechanisms that include intestinal pinocytosis for IgG and oligosaccharides, along with others such as specific transporters in the intestinal epithelial cells for AA in calves.
\end{abstract}

Key words: calf, colostrum, serum metabolomics, $\mathrm{GC} \times \mathrm{GC}-\mathrm{MS}$

Received January 5, 2017.

Accepted January 29, 2017.

${ }^{1}$ Corresponding author: mmasao@iwate-u.ac.jp

\section{INTRODUCTION}

It is important to feed calves adequate amounts of colostrum within $24 \mathrm{~h}$ after birth for dairy management because colostrum is the only source of nutrients in calves during the neonatal period. It also supplies immunity substances such as $\operatorname{IgG}$ to calves that are born without maternal transmission of IgG (Weaver et al., 2000; Chigerwe et al., 2015; MacFarlane et al., 2015). Therefore, neonatal calves that consume a sufficient amount of colostrum may grow healthy and be immune to infectious diseases that cause diarrhea and pneumonia (Furman-Fratczak et al., 2011; Raboisson et al., 2016).

The digestive tracts of mature mammals break down food contents into small molecules and then absorb them into cells via specific transporters (Chen et al., 2016; Glatz and Luiken, 2016; Satsu, 2017). For example, proteins are degraded into small peptides and AA that are absorbed by peptide and AA transporters, respectively, in the small intestine (Daniel, 2004; Bröer, 2008; Poncet and Taylor, 2013). In contrast, most neonatal mammals, including calves, can absorb colostral macromolecules such as proteins in the epithelial cells of the small intestinal brush border within a short time after birth (Staley et al., 1972; Staley and Bush, 1985; Jochims et al., 1994; Kaup et al., 1996; Moussaoui et al., 2014). It is well known that the serum concentrations of bioactive IgG are markedly increased after first colostrum ingestion (Quigley et al., 2002; MokhberDezfooli et al., 2012; Osaka et al., 2014; Elsohaby and Keefe, 2015; Yang et al., 2015). Recent studies proposed that nonspecific receptor-independent fluid pinocytosis absorb colostral IgG in the small intestine of neonates (Sockolosky and Szoka, 2015; Martins et al., 2016). Based on these previous reports, we hypothesized that colostral small molecule compounds are also absorbed by the fluid pinocytosis and transferred into the blood, resulting in a significant variation in serum levels of such compounds and their metabolites before and after first ingestion of the colostrum in calves, as is the case 
for IgG. However, surprisingly little is known about the temporal changes in serum small molecule metabolites, such as carbohydrates, AA, and lipids, in neonatal calves after first colostrum ingestion, except for some blood biochemical parameters such as glucose, BUN, nonesterified fatty acids, and triglycerides (Hammon et al., 2002; Muri et al., 2005; Blum, 2006). To test our hypothesis, we first performed a comprehensive analysis of serum metabolites before and after first colostrum ingestion in neonatal calves.

Metabolomics is a powerful method used to comprehensively profile serum metabolites (Psychogios et al., 2011; Zhang et al., 2012; Mussap et al., 2013). Gas chromatography-mass spectrometry is commonly used in metabolomics studies (Begley et al., 2009; Sun et al., 2015; Wang et al., 2016). In conventional GC-MS, because metabolites in samples are separated on a GC capillary column, peak capacity limitations, such as co-elution of several metabolites at the same retention time, often become problematic in samples with complex chemical profiles. Two-dimensional gas chromatography $(\mathbf{G C} \times \mathbf{G C})$-MS overcomes this problem by using 2 different polarity columns (i.e., nonpolar and polar columns; Almstetter et al., 2012; Weinert et al., 2015). Two different separation processes in $\mathrm{GC} \times \mathrm{GC}$ increase the separation, detection, and identification of a wide variety of metabolic compounds relative to onedimensional GC-MS (Zhang et al., 2012; Winnike et al., 2015). In $\mathrm{GC} \times \mathrm{GC}$, effluents from the first-dimension (1D) column are trapped in a temperature-controlled modulator for a couple of seconds and then injected into the second-dimension (2D) column. During the process, compounds still co-eluting at the end of the 1D separation due to similar boiling points can be separated based on their different polarities in the 2D phase. As a result, each compound is characterized by both $1 \mathrm{D}$ and $2 \mathrm{D}$ retention times; thus, $\mathrm{GC} \times \mathrm{GC}-\mathrm{MS}$ can detect hundreds to thousands more compounds than conventional GC-MS.

In the present study, we performed $\mathrm{GC} \times \mathrm{GC}-\mathrm{MS}$ based serum metabolomics in neonatal calves before and after first ingestion of colostrum. Multivariate analyses of $\mathrm{GC} \times \mathrm{GC}-\mathrm{MS}$ results characterized individual and temporal variations in calf serum metabolic profiles. These findings will give new insights to understand the metabolism and absorption processes of colostral contents in neonatal calves.

\section{MATERIALS AND METHODS}

\section{Blood Sampling from Neonatal Calves}

Five male Holstein-Friesian calves with a mean BW at birth of $47.4 \pm 3.2 \mathrm{~kg}$ were used in this experiment.
This study was approved by the Animal Research Committee and followed the Animal Experiment Guidelines of Iwate University. The physical condition of each calf was evaluated based on appearance, vitality, and blood cell counts. Approximately $20 \mathrm{~L}$ of pooled colostrum was prepared from 12 Holstein-Friesian dams. The pooled colostrum was stored at $-20^{\circ} \mathrm{C}$ until use. Protein and fat contents in the colostrum were 15.8 and $5.5 \%$, respectively. The IgG concentration of the pooled colostrum was $56.6 \mathrm{~g} / \mathrm{L}$. Calves were fed the colostrum one time at a volume of $4 \%$ of BW using a rubber nipple attached to a bucket within $4.2 \pm 0.4 \mathrm{~h}$ after birth. Blood samples were obtained from the jugular vein at 8 time points: before colostrum ingestion $(0 \mathrm{~h})$ and at $1,2,3,4,6,8$, and $12 \mathrm{~h}$ after ingestion. Serum samples were stored at $-30^{\circ} \mathrm{C}$ until further analyses. Serum IgG concentrations were measured using a commercially available bovine IgG ELISA quantitation kit (Bethyl Laboratory Inc., Montgomery, TX).

\section{Sample Preparation}

The GC-MS samples were prepared according to the previous procedures (Dunn et al., 2011). In brief, each serum sample was thawed on ice for $60 \mathrm{~min}$, and an aliquot $(100 \mu \mathrm{L})$ was transferred into a glass tube containing $400 \mu \mathrm{L}$ of acetone with propanedioic acid (1 $\mu \mathrm{g})$ as an internal standard. After mixing the samples thoroughly, the sample was centrifuged for deproteinization at room temperature at $560 \times g$ for $10 \mathrm{~min}$ at $20^{\circ} \mathrm{C}$. The supernatant was then transferred to a new glass tube and dried using a centrifugal vacuum evaporator until completely desiccated without heating. Each dried sample was derivatized using a 2-step method. First, $50 \mu \mathrm{L}$ of fresh $O$-methylhydroxylamine in pyridine $(20 \mathrm{mg} / \mathrm{mL})$ was added to the sample, and the mixture was incubated at $80^{\circ} \mathrm{C}$ for $15 \mathrm{~min}$. Next, $50 \mu \mathrm{L}$ of $N$-methyl- $N$-trimethylsilyl-trifluoroacetamide was added to the sample and the mixture was incubated for trimethylsilyl (TMS) derivatization at $80^{\circ} \mathrm{C}$ for $15 \mathrm{~min}$. Each sample was analyzed by $\mathrm{GC} \times \mathrm{GC}-\mathrm{MS}$ within $24 \mathrm{~h}$ after TMS derivatization.

\section{GCXGC-MS Analysis}

All samples were analyzed on a system containing an Agilent 7890 GC (Agilent Technologies, Santa Clara, CA) with a Gestel MPS2 autosampler (Gestel, Mülheim an der Ruhr, Germany) interfaced with a LECO Pegasus 4D time-of-flight MS (LECO Corp., St. Joseph, MI). The primary column, 30-m DB-5MS (0.25 mm i.d. $\times 0.25 \mu \mathrm{m}$ df, Agilent Technologies), and the secondary column, 1.5-m RTX-200 (0.18 mm i.d. $\times 0.25 \mu \mathrm{m}$ df, Restek Corp., Bellefonte, PA), were used for $\mathrm{GC} \times \mathrm{GC}$. 
The secondary column was placed inside the secondary column oven that was mounted inside the primary column oven after a dual-stage quad-jet thermal modulator released 2 permanent cold nitrogen jets and 2 pulsed hot air jets to trap and refocus compounds eluted from the primary column. The carrier gas, helium, was set at $1.5 \mathrm{~mL} / \mathrm{min}$. Two microliters of each TMS-derivatized sample was injected by the autosampler into an injector in splitless mode at $260^{\circ} \mathrm{C}$. The primary column temperature was programmed as follows: $70^{\circ} \mathrm{C}$ for 0.5 min, heated at $6^{\circ} \mathrm{C} / \mathrm{min}$ to $305^{\circ} \mathrm{C}$, and held for $5 \mathrm{~min}$. The secondary column temperature program was set at a parallel ramp offset by $5^{\circ} \mathrm{C}$. The total run time was approximately $50 \mathrm{~min}$. The modulation period was 5 $\mathrm{s}$ (cold jet for $1 \mathrm{~s}$ and hot jet for $1.5 \mathrm{~s}$, twice), and its temperature offset was $10^{\circ} \mathrm{C}$. For GC-MS analysis of the samples, we used the same system in which temperature of the secondary column oven was set at $250^{\circ} \mathrm{C}$ and the thermal modulator was off to pass through effluents from the primary column without separation. The MS transfer line temperature was $250^{\circ} \mathrm{C}$. A solvent delay of $3 \mathrm{~min}$ was used. Time-of-flight MS with an electron ionization source was used as a detector with a mass range of 45 to $750 \mathrm{~m} / \mathrm{z}$, acquisition rate of 200 spectra/s, ion source temperature of $240^{\circ} \mathrm{C}$, detector voltage of 1,650 V, and an electron energy of $-70 \mathrm{eV}$. All samples were analyzed in triplicate to confirm the reproducibility.

\section{Data Analysis}

We used LECO ChromaTOF software (ver. 4.50) to process the raw instrument data, including peak picking from the total ion chromatogram, sequence alignment between raw data, and the commercially available NIST08 (National Institute of Standards Technology mass spectral search program; NIST, Gaithersburg, MD), Wiley07, and the LECO/Fiehn Metabolomics (LECO Corp.) Libraries searches for metabolite identifications. All peak lists were further analyzed using a statistical software program (JMP12.2.0, SAS Institute, Cary, NC) for principal component analysis (PCA), hierarchical clustering analysis (HCA), partial least square (PLS) regression analysis, and correlation coefficients. The number of compounds detected in each sample was compared by nonparametric comparison for all pairs using the Steel-Dwass method.

\section{RESULTS}

\section{Metabolic Profiling of Calf Serum by GC×GC-MS}

In the present study, the serum metabolite profiles of 5 neonatal calves before and after first ingestion of colostrum were examined by comprehensive $\mathrm{GC} \times \mathrm{GC}$ MS. Calves did not exhibit any physiological problem throughout the experimental period. Forty serum samples were obtained from 5 calves at 8 time points beginning immediately before $(0 \mathrm{~h})$ and ending $12 \mathrm{~h}$ after first ingestion of colostrum. As each sample was analyzed by $\mathrm{GC} \times \mathrm{GC}-\mathrm{MS}$ in triplicate, $120 \mathrm{GC} \times \mathrm{GC}$ MS results were obtained from the 40 samples for multivariate analyses. Figure 1A shows representative contour plots of $\mathrm{GC} \times \mathrm{GC}-\mathrm{MS}$ total ion chromatogram of TMS-derivatized calf serum samples, which are metabolic fingerprints of the calf serum obtained at 0 and $8 \mathrm{~h}$ after first colostrum ingestion. Each spot indicates a TMS-derivatized compound. A large number of serum metabolites were detectable by $\mathrm{GC} \times \mathrm{GC}-\mathrm{MS}$ compared with that by GC-MS from the same samples (Figure 1B). By aligning the $120 \mathrm{GC} \times \mathrm{GC}-\mathrm{MS}$ results using ChromaTOF software with the chromatographic deconvolution algorithm (Mohler et al., 2006) and then eliminating unwanted background spots derived from the column bleed and chemical reagents used for sample derivatization, $1,399 \pm 48$ (mean $\pm \mathrm{SD}$ ) spots whose signal-to-noise ratios were over 100 were considered significant spots corresponding to serum metabolites in the 40 serum samples (Table 1). Approximately 1,400 spots were detected, of which 516 were consistently detected in all samples. We found no significant difference in the total number of spots between serum samples. Approximately half of all spots were designated as unknown compounds by library searches.

\section{Unbiased Characterization of Serum Metabolites}

To determine the main drivers of variance in the 5 calf serum metabolic fingerprints obtained at 8 time points, the $120 \mathrm{GC} \times \mathrm{GC}-\mathrm{MS}$ results were applied to PCA, an unsupervised technique for dimensionality reduction. Eleven principal components (PC) explained $60 \%$ of the total variation in the serum metabolic profiles. Although the first 2 PC jointly explained only $20.9 \%$ of the total variance $(\mathrm{PC} 1=11.2 \% ; \mathrm{PC} 2=9.7 \%)$, both $\mathrm{PC} 1$ and $\mathrm{PC} 2$ grouped the $120 \mathrm{GC} \times \mathrm{GC}-\mathrm{MS}$ results into 5 groups corresponding to the 5 calves (Figure $2 \mathrm{~A}$ ).

The same $120 \mathrm{GC} \times \mathrm{GC}-\mathrm{MS}$ results were also subjected to HCA, a method to group samples based on similarity in patterns and to build a hierarchy of groups. Figure 2B shows a dendrogram and a heatmap, which confirmed the PCA results. The HCA revealed the presence of 5 major clusters corresponding to the 5 calves, except for 1 sample obtained $12 \mathrm{~h}$ after ingestion from calf $\mathrm{C}$, which was categorized with a cluster of calf E samples. The HCA also provided a more detailed view of the temporal changes in metabolites in each calf. Samples taken at closely spaced time points 
A
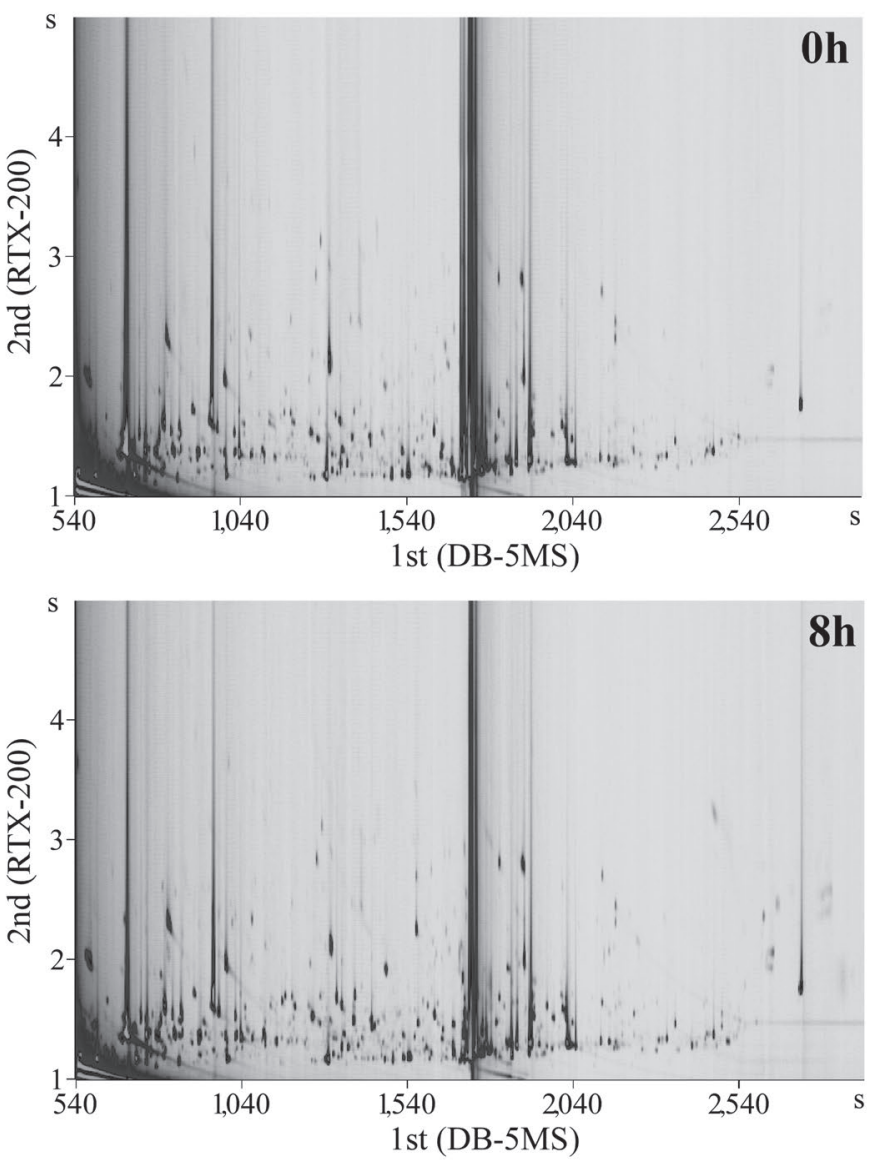

B

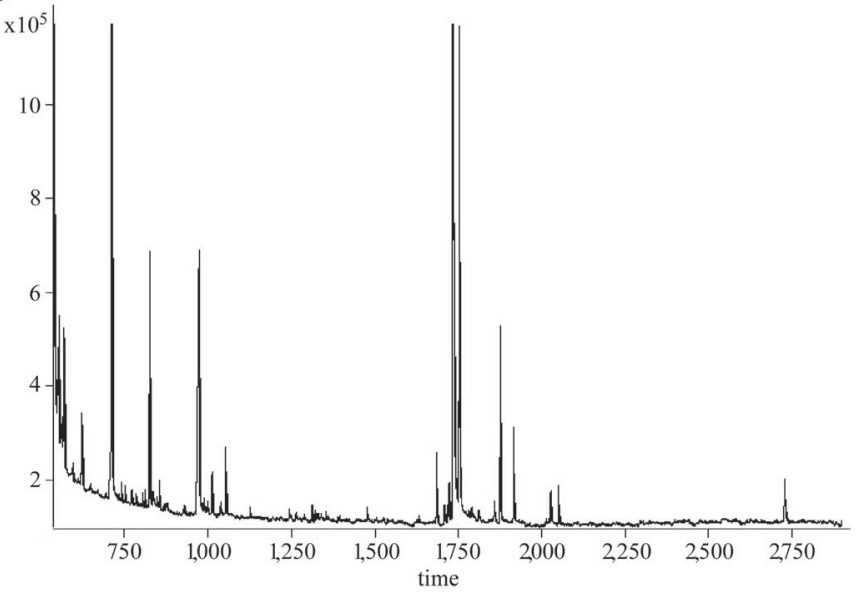

Figure 1. Two-dimensional contour plot for the total ion chromatogram signal of the trimethylsilyl (TMS)-derivatized metabolites of calf serum samples. (A) The representative 2-dimensional contour plots of TMS-derivatized samples obtained from calf $\mathrm{A}$ at 0 and $8 \mathrm{~h}$ after first colostrum ingestion; X- and Y-axes are first (DB-5MS) and second (RTX-200) retention time (s), respectively. (B) The GC-MS total ion chromatogram of the same sample (calf A, $0 \mathrm{~h}$ ); X-and Y-axes are retention time $(\mathrm{s})$ and intensity of $\mathrm{MS}$, respectively. tended to fall within the same subcluster for each calf. For example, in the metabolic data set of calf $\mathrm{B}$, the sample obtained at $0 \mathrm{~h}$ was independent of the other samples, but was related to a subcluster consisting of samples obtained at 1,2 , and $3 \mathrm{~h}$ after ingestion of colostrum. On the other hand, the samples obtained at 4 and $6 \mathrm{~h}$ produced a separate subcluster that was associated with the samples obtained at 8 and at $12 \mathrm{~h}$. Similar temporal patterns were also observed in other calves. Taken together, these analyses identified over 1,000 spots corresponding to small molecule compounds that were present in the serum before colostrum ingestion and that reflected individual differences among the 5 calves. In addition, these spots showed temporal changes after colostrum ingestion that were unique to each individual calf.

\section{Serum Metabolites Whose Temporal Changes Are Correlated with Serum IgG}

Individual differences in serum metabolite profiles among the calves prevented the discovery of metabolites showing temporal changes after ingestion of the first colostrum. Therefore, we next examined compounds whose temporal changes were similar to those of serum IgG after the first colostrum ingestion. We calculated correlation coefficients between serum IgG and each metabolite in each calf $(24 \mathrm{GC} \times \mathrm{GC}-\mathrm{MS}$ results obtained by triplicate analysis of 8 different time points in each calf). We identified an average of 139 \pm 27 metabolites whose temporal changes showed a high positive correlation coefficient (over 0.7) with changes in IgG in each calf. Conversely, by calculating the correlation coefficients between serum IgG and each metabolite across the 5 calves using $120 \mathrm{GC} \times \mathrm{GC}-\mathrm{MS}$ results, only 14 serum metabolites showed a high positive correlation (over 0.7 ) with IgG changes (Table 2). Considering the maximum concentration of serum IgG and the time at which the maximum concentration was reached in calves $\mathrm{A}, \mathrm{D}$, and $\mathrm{E}$ (over $10 \mathrm{~g} / \mathrm{L}$ up to $6 \mathrm{~h}$ ) and calves B and C (under $5.5 \mathrm{~g} / \mathrm{L}$ at $12 \mathrm{~h}$ ), we focused on 8 of the 14 metabolites whose temporal changes and individual variations were similar to those of serum IgG (Figure 3A) in contrast to the other 6 compounds, whose maximum concentrations and temporal changes showed no difference among the 5 calves or a pattern different from that of IgG (Supplementary Figure S1; https://doi.org/10.3168/jds.2017-12557). Based on the fragmentation patterns of MS electron ionizationspectra and retention time, 3 of the 8 compounds were identified as TMS derivatives of lactose, galactoside, and 2-pyrrolidone-5-carboxylic acid. Although we could not identify the chemical structures of the other 5 compounds whose MS spectra are shown in Supplementary 
Table 1. Average number of compounds detected in each time point in 5 calves

\begin{tabular}{|c|c|c|c|c|c|c|c|c|c|}
\hline \multirow[b]{2}{*}{ Item } & \multicolumn{8}{|c|}{ Time after first ingestion of colostrum (h) } & \multirow[b]{2}{*}{ Total average } \\
\hline & 0 & 1 & 2 & 3 & 4 & 6 & 8 & 12 & \\
\hline Average & 1,351 & 1,376 & 1,390 & 1,369 & 1,416 & 1,429 & 1,439 & 1,423 & 1,399 \\
\hline SD & 12 & 30 & 17 & 98 & 24 & 20 & 34 & 29 & 48 \\
\hline
\end{tabular}

Figure S2 (https://doi.org/10.3168/jds.2017-12557), unknown compound 3 and 4 would be oligosaccharides based on their mass spectra, which include characteristic $m / z$ 191, 204, and 217 ions for oligosaccharides (Mogoşanu et al., 2011).

In the $\mathrm{PCA}$ of the 8 metabolites, the first $2 \mathrm{PC}$ jointly explained $80.5 \%$ of the total variance $(\mathrm{PC} 1=$ $68.7 \%$; $\mathrm{PC} 2=11.8 \%)$. The $120 \mathrm{GC} \times \mathrm{GC}-\mathrm{MS}$ results were divided into 2 groups (Figure 3B). The first group comprised all samples from calves $\mathrm{B}$ and $\mathrm{C}$, as well as those from calf A obtained until $3 \mathrm{~h}$, calf $\mathrm{D}$ obtained until $4 \mathrm{~h}$, and calf $\mathrm{E}$ obtained until $2 \mathrm{~h}$ after ingestion. The second group consisted of other samples from calves A, D, and E. Serum IgG levels for the first and second groups were under and over $7 \mathrm{~g} / \mathrm{L}$, respectively. These results suggest that temporal changes in these 8 compounds are correlated with those in serum IgG after first colostrum ingestion.

These results were also evaluated by PLS regression analysis using $120 \mathrm{GC} \times \mathrm{GC}-\mathrm{MS}$ results comprising the 8 metabolites. A significant relationship between the 8 compounds (matrix X) and IgG level (matrix Y) was observed by a prediction model for IgG (Figure 3C). The PLS model was validated using 4 factors according to the minimum root mean predicted residual sum of squares of 0.332296 , computed by nonlinear iterative partial least squares. The model described 85.8 and $91.1 \%$ of the variation in $\mathrm{X}$ and $\mathrm{Y}$, respectively, and the cumulative $\mathrm{Q}^{2}$, an indicator of the predictive ability of the model, was 0.999761. Large variable importance in the projection values are identified as high relevance for explaining Y. The values of all the 8 compounds were more than 0.8 , which indicates that they are significant in producing a prediction model for serum IgG level. In conclusion, the serum IgG level can be predicted by these 8 compounds, which are candidate compounds absorbed via fluid pinocytosis with colostral IgG.

\section{Serum Metabolites that Increase After Colostrum Ingestion}

The finding that only a limited number of serum metabolites were correlated with IgG in all 5 calves was unexpected. We had hypothesized that more compounds may be absorbed from the colostrum by fluid pinocytosis along with $\operatorname{IgG}$ and that such compounds would show a marked increase in the serum after ingestion. Therefore, we aimed to identify serum metabolites that increased in a time-dependent manner, but one that differed from that of the serum IgG level. The correlation coefficient was calculated for each sampling time and each metabolite using the $120 \mathrm{GC} \times \mathrm{GC}-\mathrm{MS}$ results. Ten serum metabolites showed a highly positive correlation (over 0.7 ) with the sampling time (Table 3 ). In this analysis, we focused on 4 compounds: 3 were TMS derivatives of Met, Thr, and Trp (EAA in cows) and the other focal compound was a TMS-derivative of phenylacetic acid that is a metabolite of Phe (Figure 4). These compounds increased close to $12 \mathrm{~h}$ after ingestion in all 5 calves in a similar manner, but differ from temporal patterns of IgG and lactose. The TMS derivative of phenylacetic acid sustained a low level in all 5 calves until $6 \mathrm{~h}$ after ingestion, and then drastically increased from $6 \mathrm{~h}$ in calf $\mathrm{A}$ and $\mathrm{C}$, from $8 \mathrm{~h}$ in calf $\mathrm{B}$ and $\mathrm{D}$, and from $12 \mathrm{~h}$ in calf $\mathrm{E}$. Based on these results, we also examined the temporal changes in other EAA. The TMS derivatives of Phe, Ile, Leu, Lys, Arg, His, and Val were also detectable as calf serum metabolites, but not all 5 calves showed increases of these compounds after ingestion in similar manner (Supplementary Figure S3; https://doi.org/10.3168/jds.2017-12557). These results indicate that Met, Thr, and Trp increase universally in calves after first colostrum ingestion.

\section{DISCUSSION}

There are a few reports on GC-MS-based serum metabolomics in cows and calves (Dettmer et al., 2010; Anizan et al., 2012; Janssens et al., 2013; Zhang et al., 2013; Sun et al., 2015); however, as serum metabolite profiles in mammals comprise a large number of compounds, conventional GC using a capillary column is limited by peak capacity. Considering the necessity to detect as many serum metabolites as possible for comprehensive nontarget metabolomics, we first applied $\mathrm{GC} \times \mathrm{GC}-\mathrm{MS}$ to calf serum metabolomics to compare temporal changes beginning with the time point immediately before until $12 \mathrm{~h}$ after first ingestion of colostrum. In our analysis, approximately 180 peaks were detectable with a signal-to-noise ratio of 100 or more 
A

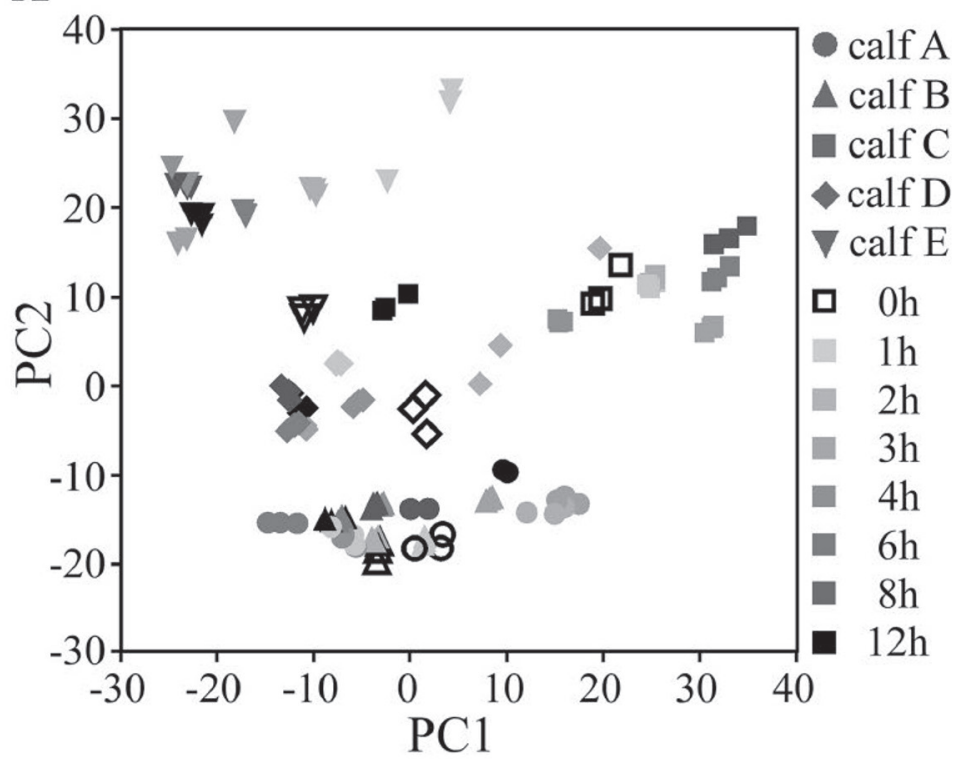

B

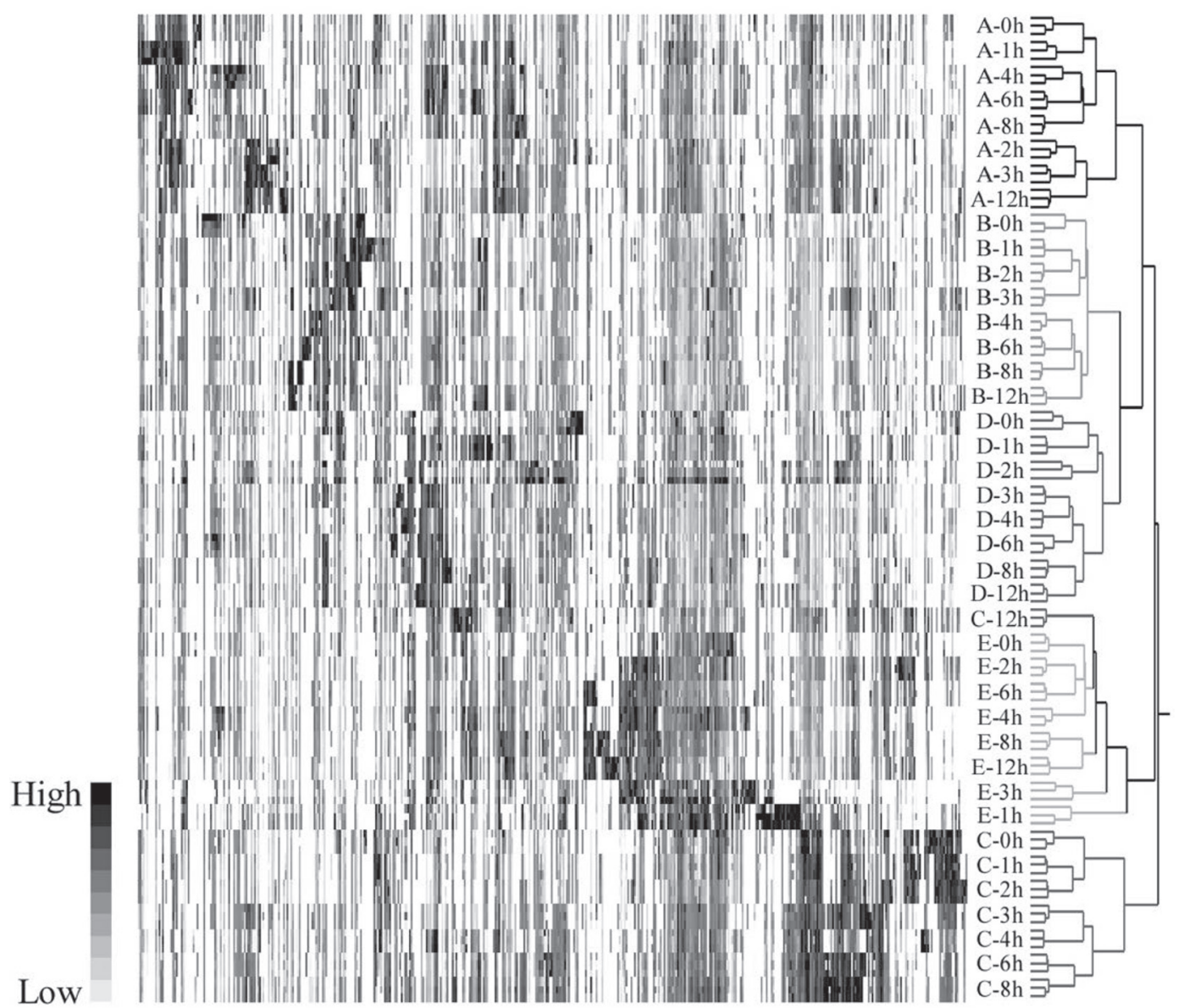

Figure 2. Unbiased characterization of serum metabolites obtained from 5 calves. (A) Principal component analysis (PCA) score plot of the 120 two-dimensional gas chromatography mass spectrometry (GC $\times$ GC-MS) results of trimethylsilyl (TMS)-derivatized samples obtained from 5 neonatal calves at 8 time points between 0 and $12 \mathrm{~h}$ after first colostrum ingestion. Principal component (PC) 1 and PC2 explain 11.2 and $9.7 \%$ of the total variance, respectively. (B) Heat map and dendrogram of the 120 GC $\times$ GC-MS results of the TMS-derivatized samples. Ward's minimum variance was used for hierarchical clustering. 
Table 2. Metabolites whose correlation coefficients with IgG were over 0.7

\begin{tabular}{|c|c|c|c|c|}
\hline $1 \mathrm{DRT}^{1}(\mathrm{~s})$ & $2 \mathrm{DRT}^{2}(\mathrm{~s})$ & Compound name ${ }^{3}$ & $\begin{array}{l}\text { Correlation coefficient } \\
\text { with IgG }\end{array}$ & $P$-value \\
\hline $2,508.73$ & 1.61 & Unknown 1 & 0.9 & $<0.0001$ \\
\hline $1,324.55$ & 1.68 & $\begin{array}{l}\text { 2-Pyrrolidone-5-carboxylic } \\
\text { acid-TMS }\end{array}$ & 0.8 & $<0.0001$ \\
\hline $2,104.44$ & 1.19 & D-Galactoside-TMS & 0.8 & $<0.0001$ \\
\hline $1,900.00$ & 2.08 & Unknown 6 & 0.8 & $<0.0001$ \\
\hline $2,610.07$ & 2.35 & Unknown 2 & 0.8 & $<0.0001$ \\
\hline 800.17 & 2.60 & Unknown 7 & 0.7 & $<0.0001$ \\
\hline $1,865.00$ & 2.19 & Unknown 8 & 0.7 & $<0.0001$ \\
\hline $2,524.15$ & 1.34 & Unknown 3 (oligosaccharide) ${ }^{4}$ & 0.7 & $<0.0001$ \\
\hline $1,375.19$ & 1.61 & Unknown 9 & 0.7 & $<0.0001$ \\
\hline $2,591.55$ & 1.47 & Unknown 4 (oligosaccharide) ${ }^{4}$ & 0.7 & $<0.0001$ \\
\hline $2,503.72$ & 1.32 & Lactose-TMS & 0.7 & $<0.0001$ \\
\hline $1,669.88$ & 1.44 & Unknown 5 & 0.7 & $<0.0001$ \\
\hline $1,375.00$ & 1.49 & Pentanedioic acid-TMS & 0.7 & $<0.0001$ \\
\hline $2,647.60$ & 2.45 & Unknown 10 (oligosaccharide) $^{4}$ & 0.7 & $<0.0001$ \\
\hline
\end{tabular}

in calf serum samples by GC-MS, whereas $\mathrm{GC} \times \mathrm{GC}$ MS detected approximately 1,400 peaks in the same samples. Peaks corresponding to oligosaccharides, such as lactose, which showed temporal changes similar to those of $\mathrm{IgG}$, were detectable on $\mathrm{GC} \times \mathrm{GC}$-MS but not on GC-MS, as they are co-eluted with other compounds at the same retention time. Therefore, we concluded that $\mathrm{GC} \times \mathrm{GC}-\mathrm{MS}$ is useful for serum metabolomics in calves.

A major finding of our study is that oligosaccharides, including lactose, are detectable in calf serum, and their contents are significantly increased with IgG after first colostrum ingestion. Oligosaccharides are normally decomposed to monosaccharides by glycosidases in the gut, and then the monosaccharides are absorbed from the brush border in the small intestine (Shirazi-Beechey et al., 1995). In neonatal mammals, lactase hydrolyzes lactose, whose content in the colostrum is approximately $2.5 \%$ (Kehoe et al., 2007), into glucose and galactose, which are absorbed in the small intestine. Therefore, our results suggest that oligosaccharides such as lactose are absorbed by the receptor-independent fluid pinocytosis in neonatal calves, thereby significantly increasing their serum contents, similar to the process for IgG after first colostrum ingestion.

Some EAA in cows, such as Thr, Trp, and Met, and a Phe metabolite, phenylacetic acid, increased in a time-dependent manner in all 5 calves tested in our study. Although we did not observe significant temporal increases in other EAA, such as Phe, Ile, Leu, Lys, Arg, His, and Val, among all 5 calves, all of these AA showed temporal increases in some of the 5 calves. Interestingly, the temporal changes in these EAA showed a low correlation with those of serum $\operatorname{IgG}$ and lactose. These results suggest that these EAA may be derived from colostrum via AA transporters expressed in the epithelial cells of the small intestine, and not by receptor-independent fluid pinocytosis. We propose that not only pinocytosis but also transporters function for the absorption of small molecule colostrum compounds in neonatal calves and that the absorption mechanisms in neonatal calves within $24 \mathrm{~h}$ after birth are more complex than we once believed.

Before initiating this study, we hypothesized that a large number of small molecule metabolites would be increased in calf serum after first colostrum ingestion by the pinocytosis of colostral contents, as well as that of IgG. However, GC $\times$ GC-MS-based metabolomics of calf serum revealed that only a limited number of serum metabolites showed temporal increases in all 5 calves after ingestion. This result was likely caused by individual differences in serum metabolites that showed temporal changes, given that over 100 metabolites, as well as IgG, were increased in each calf. This indicates that a large number of serum metabolites in each calf showed temporal changes after ingestion, but for only a few compounds were these patterns common to all 5 calves. In contrast to laboratory inbred mouse strains, differences in the genetic background among calves, environmental factors, and methodological differences, such as the date of experiment, may be involved in the metabolic differences observed, which in turn result in temporal changes in serum metabolites.

It is well known that huge variations exist in colostrum quality among individual dams (Kehoe et al., 2007); therefore, our future plans are to examine relationships 

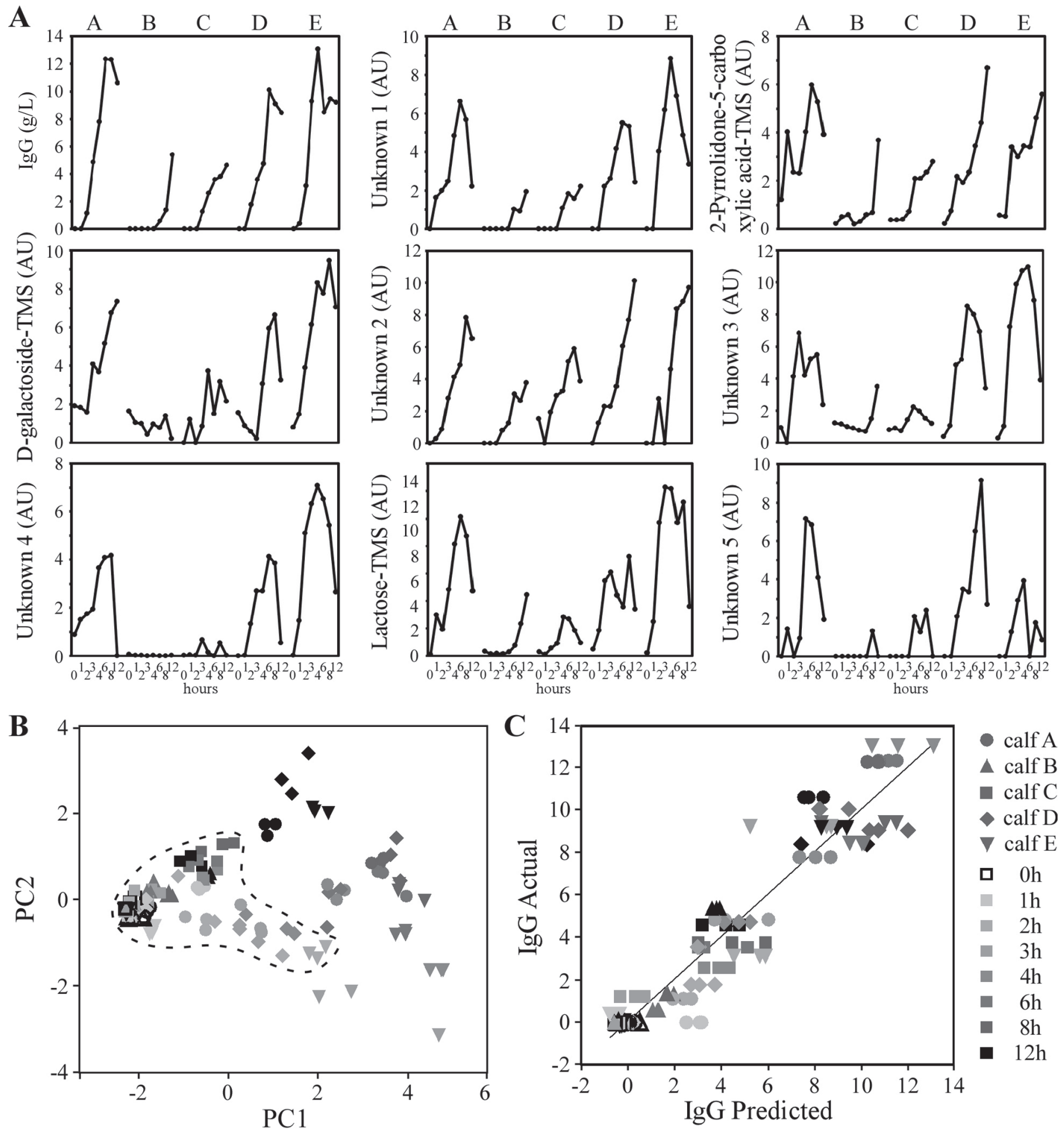

Figure 3. Serum metabolites that show similar temporal changes and individual variations with serum IgG levels in 5 calves. (A) Headers A to E indicate calf A to E, respectively. The $\mathrm{x}$-axis shows time (h) after first colostrum ingestion; $\mathrm{y}$-axis shows serum IgG concentration and arbitrary units corresponding to average of 3 replicate peak area values of each metabolite. Mass spectra of unknown compounds are shown in Supplementary Figure S2 (https://doi.org/10.3168/jds.2017-12557). (B) Principal component analysis score using 120 two-dimensional gas chromatography mass spectrometry $(\mathrm{GC} \times \mathrm{GC}-\mathrm{MS})$ results comprising the 8 metabolites. Principal component (PC) 1 and $\mathrm{PC} 2$ explain 68.7 and $11.8 \%$ of the total variance, respectively. The dashed circle indicates samples whose serum IgG levels were under $7 \mathrm{~g} / \mathrm{L}$. (C) Relationship between actual and predicted serum IgG of the partial least squares model using 120 GC $\times$ GC-MS results comprising the 8 metabolites. 

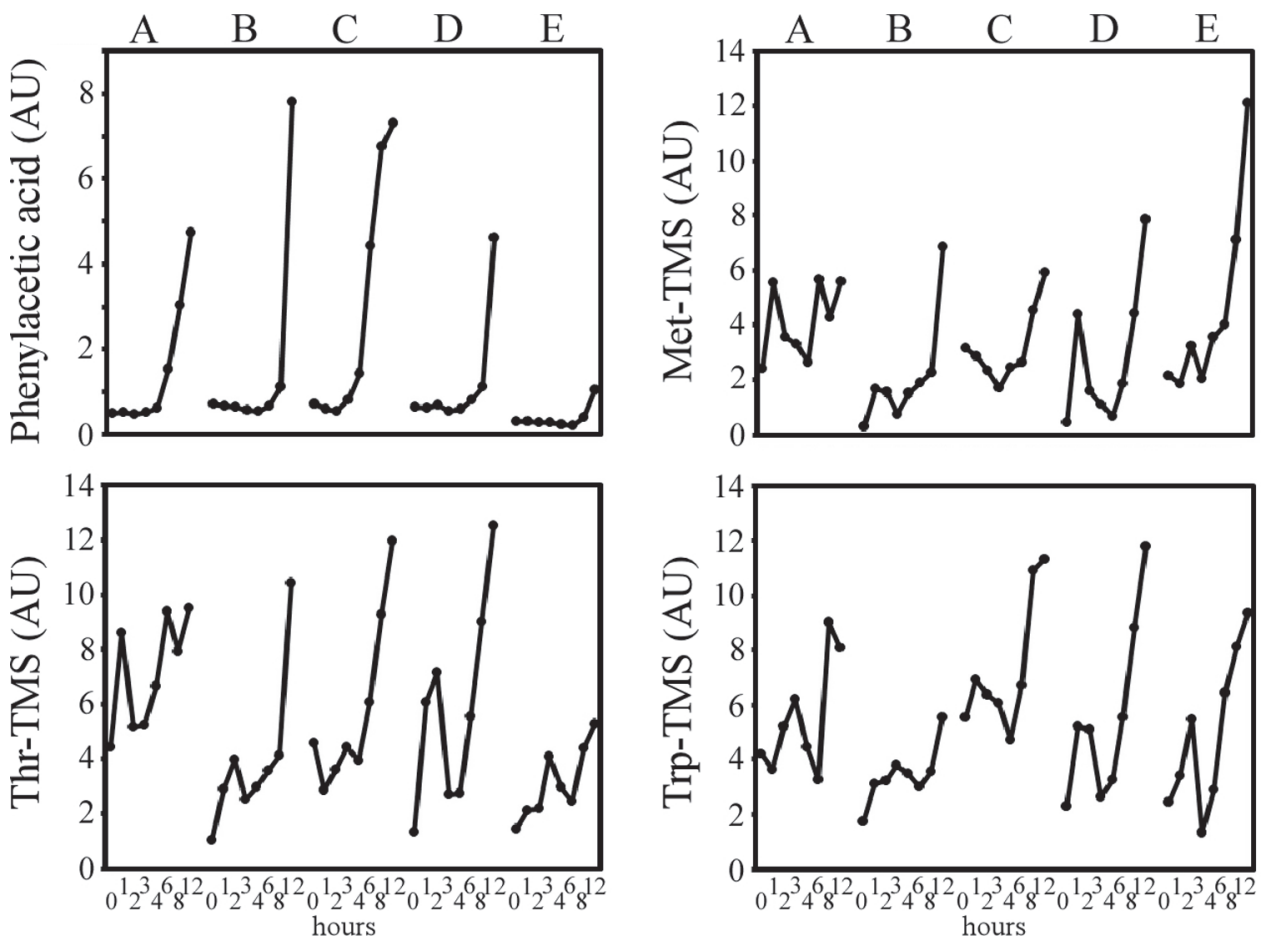

Figure 4. Serum metabolites that show a high positive correlation coefficient (over 0.7) with time after colostrum ingestion in 5 calves. Headers A to E indicate calves A to E, respectively. The $\mathrm{x}$-axis is time (h) after first colostrum ingestion; y-axis shows arbitrary units of average of 3 replicate peak area values of each metabolite.

between colostrum quality and serum metabolomics and between colostrum contents of metabolites and serum IgG levels. However, the current study suggests that it is not easy to examine these relationships in neonatal calves because we found individual variation in temporal changes of serum IgG and small molecule metabolites among even calves that were fed the same pooled colostrum. This indicates that, when we compare metabolic differences between calves fed high- and low-quality colostrum, we have to pay attention to not only colostrum quality, but also individual differences of calves. The GC $\times$ GC-MS-based metabolomics of calf serum will provide valuable information to demonstrate these relationships.

The oligosaccharides, including lactose, and EAA, such as Met, Thr, and Trp, that we focused on may be important colostrum nutrients for neonatal calves. Administration of these compounds to calves with dis-

Table 3. Metabolites whose correlation coefficients with time were over 0.7

\begin{tabular}{|c|c|c|c|c|c|}
\hline $1 \mathrm{DRT}^{1}(\mathrm{~s})$ & $2 \mathrm{DRT}^{2}(\mathrm{~s})$ & Compound name ${ }^{3}$ & \multicolumn{2}{|c|}{ Correlation coefficient with } & $P$-value \\
\hline $2,610.07$ & 2.35 & Unknown 2 & 0.8 & 0.8 & $<0.0001$ \\
\hline $1,448.72$ & 1.48 & Phenylacetic acid-TMS & 0.7 & 0.2 & $<0.0001$ \\
\hline $1,170.06$ & 1.69 & Met-TMS & 0.7 & 0.5 & $<0.0001$ \\
\hline $1,019.94$ & 1.53 & Thr-TMS & 0.7 & 0.4 & $<0.0001$ \\
\hline $1,603.70$ & 2.19 & Unknown 11 & 0.7 & 0.6 & $<0.0001$ \\
\hline $1,324.55$ & 1.68 & 2-Pyrrolidone-5-carboxylic acid-TMS & 0.7 & 0.8 & $<0.0001$ \\
\hline $2,014.10$ & 1.52 & Trp-TMS & 0.7 & 0.3 & $<0.0001$ \\
\hline
\end{tabular}

${ }^{1}$ First-dimension retention time.

${ }^{2}$ Second-dimension retention time.

${ }^{3}$ Temporal changes of compounds indicated in bold are shown in Figure 4. TMS $=$ trimethylsilyl. 
eases, supplementation of these compounds into milk replacer, and quantifications of colostrum contents of these compounds for determination of colostrum quality will be worthwhile for calf management. Furthermore, these compounds may represent potential biomarkers that can be used to determine whether calves absorb a sufficient amount of nutrients from colostrum in the neonatal period. Further studies, such as chemical identifications of unknown compounds and target analysis of these compounds in several calves, are necessary to develop novel biomarkers for the management of dairy calves.

\section{CONCLUSIONS}

This is the first study to perform GC $\times$ GC-MS-based serum metabolomics in calves. The GC $\times$ GC-MS method detected approximately 1,400 calf serum metabolites, a number that was markedly larger compared with conventional GC-MS, which detected approximately 180 metabolites in the same serum samples. The primary characterization of calf serum metabolic profiles before and after first ingestion of colostrum revealed individual differences among the calves rather than predictable temporal changes after the ingestion. Surprisingly, only a limited number of serum metabolites, such as oligosaccharides, including lactose, changed temporally in a pattern similar to that observed for serum IgG in all tested calves universally. Considering that oligosaccharides are generally absorbed after degradation to monosaccharides, serum oligosaccharides such as lactose would be derived from colostrum. Colostrum oligosaccharides may be absorbed by fluid pinocytosis, along with IgG, in the brush border of the small intestine. In contrast, some EAA showed temporal increases after ingestion, but not a high correlation with IgG, indicating that these AA are absorbed by AA transporters rather than by pinocytosis. These data suggest complex mechanisms for the absorption of small molecule compounds in neonatal calves. Serum metabolomics based on $\mathrm{GC} \times \mathrm{GC}-\mathrm{MS}$ are useful for improving our understanding of neonatal calf physiology and metabolism.

\section{ACKNOWLEDGMENTS}

This work was supported in part by Grant-in-Aid for Scientific Research on Priority Areas from the Japan Society for the Promotion of Science (grant 12J40129). T. Miyazaki was supported by a Grant-in-Aid for JSPS fellows. We thank Y. Endo from Iwate University for sample preparation and S. Sato and M. Takahashi from Iwate University for invaluable discussion.

\section{REFERENCES}

Almstetter, M. F., P. J. Oefner, and K. Dettmer. 2012. Comprehensive two-dimensional gas chromatography in metabolomics. Anal. Bioanal. Chem. 402:1993-2013.

Anizan, S., E. Bichon, T. Duval, F. Monteau, N. Cesbron, J. P. Antignac, and B. Le Bizec. 2012. Gas chromatography coupled to mass spectrometry-based metabolomic to screen for anabolic practices in cattle: identification of 5alpha-androst-2-en-17-one as new biomarker of 4-androstenedione misuse. J. Mass Spectrom. 47:131-140.

Begley, P., S. Francis-McIntyre, W. B. Dunn, D. I. Broadhurst, A. Halsall, A. Tseng, J. Knowles, R. Goodacre, and D. B. Kell. 2009. Development and performance of a gas chromatography-time-offlight mass spectrometry analysis for large-scale nontargeted metabolomic studies of human serum. Anal. Chem. 81:7038-7046.

Blum, J. W. 2006. Nutritional physiology of neonatal calves. J. Anim. Physiol. Anim. Nutr. (Berl.) 90:1-11.

Bröer, S. 2008. Amino acid transport across mammalian intestinal and renal epithelia. Physiol. Rev. 88:249-286.

Chen, L., B. Tuo, and H. Dong. 2016. Regulation of intestinal glucose absorption by ion channels and transporters. Nutrients 8:43. https://doi.org/10.3390/nu8010043.

Chigerwe, M., J. V. Hagey, and S. S. Aly. 2015. Determination of neonatal serum immunoglobulin $\mathrm{G}$ concentrations associated with mortality during the first 4 months of life in dairy heifer calves. J. Dairy Res. 82:400-406.

Daniel, H. 2004. Molecular and integrative physiology of intestinal peptide transport. Annu. Rev. Physiol. 66:361-384.

Dettmer, K., M. F. Almstetter, I. J. Appel, N. Nurnberger, G. Schlamberger, W. Gronwald, H. H. Meyer, and P. J. Oefner. 2010. Comparison of serum versus plasma collection in gas chromatographymass spectrometry-based metabolomics. Electrophoresis 31:23652373.

Dunn, W. B., D. Broadhurst, P. Begley, E. Zelena, S. Francis-McIntyre, N. Anderson, M. Brown, J. D. Knowles, A. Halsall, J. N. Haselden, A. W. Nicholls, I. D. Wilson, D. B. Kell, and R. Goodacre. 2011. Procedures for large-scale metabolic profiling of serum and plasma using gas chromatography and liquid chromatography coupled to mass spectrometry. Nat. Protoc. 6:1060-1083.

Elsohaby, I., and G. P. Keefe. 2015. Preliminary validation of a calfside test for diagnosis of failure of transfer of passive immunity in dairy calves. J. Dairy Sci. 98:4754-4761.

Furman-Fratczak, K., A. Rzasa, and T. Stefaniak. 2011. The influence of colostral immunoglobulin concentration in heifer calves' serum on their health and growth. J. Dairy Sci. 94:5536-5543.

Glatz, J. F., and J. J. Luiken. 2016. From fat to FAT (CD36/SR-B2): Understanding the regulation of cellular fatty acid uptake. Biochimie https://doi.org/10.1016/j.biochi.2016.12.007.

Hammon, H. M., G. Schiessler, A. Nussbaum, and J. W. Blum. 2002. Feed intake patterns, growth performance, and metabolic and endocrine traits in calves fed unlimited amounts of colostrum and milk by automate, starting in the neonatal period. J. Dairy Sci. 85:3352-3362.

Janssens, G., S. Mangelinckx, D. Courtheyn, S. Prevost, G. De Poorter, N. De Kimpe, and B. Le Bizec. 2013. Application of gas chromatography-mass spectrometry/combustion/isotope ratio mass spectrometry (GC-MS/C/IRMS) to detect the abuse of 17betaestradiol in cattle. J. Agric. Food Chem. 61:7242-7249.

Jochims, K., F. J. Kaup, W. Drommer, and M. Pickel. 1994. An immunoelectron microscopic investigation of colostral $\operatorname{IgG}$ absorption across the intestine of newborn calves. Res. Vet. Sci. 57:75-80.

Kaup, F. J., W. Drommer, K. Jochims, and M. Pickel. 1996. Ultrastructure of pre- and postcolostral enterocytes of the newborn calf. Anat. Histol. Embryol. 25:249-255.

Kehoe, S. I., B. M. Jayarao, and A. J. Heinrichs. 2007. A survey of bovine colostrum composition and colostrum management practices on Pennsylvania dairy farms. J. Dairy Sci. 90:4108-4116.

MacFarlane, J. A., D. H. Grove-White, M. D. Royal, and R. F. Smith. 2015. Identification and quantification of factors affecting neona- 
tal immunological transfer in dairy calves in the UK. Vet. Rec. 176:625.

Martins, J. P., P. J. Kennedy, H. A. Santos, C. Barrias, and B. Sarmento. 2016. A comprehensive review of the neonatal Fc receptor and its application in drug delivery. Pharmacol. Ther. 161:22-39.

Mogoşanu, G. D., A. M. Grumezescu, D. E. Mihaiescu, D. Istrati, D. E. Mogoşanu, and S. A. Buteică. 2011. Identification of sugars from silene albae herba using GC-MS technique. U.P.B. Sci. Bull. B 73:101-108.

Mohler, R. E., K. M. Dombek, J. C. Hoggard, E. T. Young, and R. E. Synovec. 2006. Comprehensive two-dimensional gas chromatography time-of-flight mass spectrometry analysis of metabolites in fermenting and respiring yeast cells. Anal. Chem. 78:2700-2709.

Mokhber-Dezfooli, M. R., M. Nouri, M. Rasekh, and P. D. Constable. 2012. Effect of abomasal emptying rate on the apparent efficiency of colostral immunoglobulin G absorption in neonatal HolsteinFriesian calves. J. Dairy Sci. 95:6740-6749.

Moussaoui, N., V. Braniste, A. Ait-Belgnaoui, M. Gabanou, S. Sekkal, M. Olier, V. Theodorou, P. G. Martin, and E. Houdeau. 2014. Changes in intestinal glucocorticoid sensitivity in early life shape the risk of epithelial barrier defect in maternal-deprived rats. PLoS One 9:e88382.

Muri, C., T. Schottstedt, H. M. Hammon, E. Meyer, and J. W. Blum. 2005. Hematological, metabolic, and endocrine effects of feeding vitamin A and lactoferrin in neonatal calves. J. Dairy Sci. 88:1062-1077.

Mussap, M., R. Antonucci, A. Noto, and V. Fanos. 2013. The role of metabolomics in neonatal and pediatric laboratory medicine. Clin. Chim. Acta 426:127-138.

Osaka, I., Y. Matsui, and F. Terada. 2014. Effect of the mass of immunoglobulin (Ig) $\mathrm{G}$ intake and age at first colostrum feeding on serum IgG concentration in Holstein calves. J. Dairy Sci. 97:66086612 .

Poncet, N., and P. M. Taylor. 2013. The role of amino acid transporters in nutrition. Curr. Opin. Clin. Nutr. Metab. Care 16:57-65.

Psychogios, N., D. D. Hau, J. Peng, A. C. Guo, R. Mandal, S. Bouatra, I. Sinelnikov, R. Krishnamurthy, R. Eisner, B. Gautam, N. Young, J. Xia, C. Knox, E. Dong, P. Huang, Z. Hollander, T. L. Pedersen, S. R. Smith, F. Bamforth, R. Greiner, B. McManus, J. W. Newman, T. Goodfriend, and D. S. Wishart. 2011. The human serum metabolome. PLoS One 6:e16957.

Quigley, J. D., III, C. J. Kost, and T. M. Wolfe. 2002. Absorption of protein and $\operatorname{IgG}$ in calves fed a colostrum supplement or replacer. J. Dairy Sci. 85:1243-1248.

Raboisson, D., P. Trillat, and C. Cahuzac. 2016. Failure of passive immune transfer in calves: A meta-analysis on the consequences and assessment of the economic impact. PLoS One 11:e0150452.
Satsu, H. 2017. Molecular and cellular studies on the absorption, function, and safety of food components in intestinal epithelial cells. Biosci. Biotechnol. Biochem. https://doi.org/10.1080/09168451.2 016.1259552.

Shirazi-Beechey, S. P., I. S. Wood, J. Dyer, D. Scott, and T. P. King. 1995. Intestinal sugar transport in ruminants. Pages 117-131 in Ruminant Physiology: Digestion, Metabolism, Growth and Reproduction. Ferdinand Enke Verlag, Stuttgart, Germany.

Sockolosky, J. T., and F. C. Szoka. 2015. The neonatal Fc receptor, FcRn, as a target for drug delivery and therapy. Adv. Drug Deliv. Rev. 91:109-124.

Staley, T. E., and L. J. Bush. 1985. Receptor mechanisms of the neonatal intestine and their relationship to immunoglobulin absorption and disease. J. Dairy Sci. 68:184-205.

Staley, T. E., L. D. Corley, L. J. Bush, and E. W. Jones. 1972. The ultrastructure of neonatal calf intestine and absorption of heterologous proteins. Anat. Rec. 172:559-579.

Sun, H. Z., D. M. Wang, B. Wang, J. K. Wang, H. Y. Liu, L. Guan, and J. X. Liu. 2015. Metabolomics of four biofluids from dairy cows: Potential biomarkers for milk production and quality. J. Proteome Res. 14:1287-1298.

Wang, D., X. Wang, J. Kong, J. Wu, and M. Lai. 2016. GC-MS-based metabolomics discovers a shared serum metabolic characteristic among three types of epileptic seizures. Epilepsy Res. 126:83-89.

Weaver, D. M., J. W. Tyler, D. C. VanMetre, D. E. Hostetler, and G. M. Barrington. 2000. Passive transfer of colostral immunoglobulins in calves. J. Vet. Intern. Med. 14:569-577.

Weinert, C. H., B. Egert, and S. E. Kulling. 2015. On the applicability of comprehensive two-dimensional gas chromatography combined with a fast-scanning quadrupole mass spectrometer for untargeted large-scale metabolomics. J. Chromatogr. A 1405:156-167.

Winnike, J. H., X. Wei, K. J. Knagge, S. D. Colman, S. G. Gregory, and X. Zhang. 2015. Comparison of GC-MS and GCxGC-MS in the analysis of human serum samples for biomarker discovery. J. Proteome Res. 14:1810-1817.

Yang, M., Y. Zou, Z. H. Wu, S. L. Li, and Z. J. Cao. 2015. Colostrum quality affects immune system establishment and intestinal development of neonatal calves. J. Dairy Sci. 98:7153-7163.

Zhang, A., H. Sun, and X. Wang. 2012. Serum metabolomics as a novel diagnostic approach for disease: a systematic review. Anal. Bioanal. Chem. 404:1239-1245.

Zhang, H., L. Wu, C. Xu, C. Xia, L. Sun, and S. Shu. 2013. Plasma metabolomic profiling of dairy cows affected with ketosis using gas chromatography/mass spectrometry. BMC Vet. Res. 9:186. 